\title{
The Effect of Scale on Smoke Emission
}

\author{
G. W. MULHOLLAND, V. HENZEL ${ }^{1}$, and V. BABRAUSKAS \\ National Bureau of Standards \\ Gaithersburg, Maryland 20899, USA
}

\section{ABSTRACT}

Parallel instrumentation for measuring fire smoke aerosols have been developed in bench scale as part of the Cone calorimeter, and in large scale in a specially built measuring rig. Since the principles of design were similar, data could be directly compared. For solid and liquid combustibles, it was found that large-scale smoke emission rates could be we11 represented from Cone Calorimeter data if the specimen mass loss rates per unit area, were matched for the two cases. The matching of the mass loss rates was accomplished in bench scale by exposing the specimen to a suitable level of external irradiance. The results are presented in terms of the specific extinction area, which is defined as the smoke extinction cross-section, per unit mass. The specific extinction area, when computed on a smoke particulate mass basis, was seen to be independent of fuel type and of the conditions of test.

\section{INTRODUCTION}

Smoke produced in fires is a major concern. The emission of thermal radiation from smoke particulate in the flame plays a dominant role in fire spread. The reduced visibility caused by smoke is a significant impediment to persons escaping from fires. In addition to these issues, there is now a concern that smoke from fires ignited by the radiant flux from muclear blasts could affect the global climate. Crutzen and Birks [1] and Turco et al. [2], both predicted a temperature reduction of more than $20^{\circ} \mathrm{C}$ for the northern hemisphere, assuming a major nuclear exchange in July. There is a very large uncertainty in this prediction due to the uncertainty in estimating the amount of smoke emitted, its light absorbing tendency, and its lifetime in the atmosphere. The National Academy of Sciences report [3] contains plausible ranges for these parameters that typically span an order of magnitude.

The focus of this paper concerns the accurate determination of smoke emission and its optical properties. These are necessary (a) for reducing the uncertainty in the prediction of global climate effects resulting from a nuclear exchange and (b) for improved modeling of reduction in visibility resulting from a building fire. While there have been some small-scale studies on smoke emission by Bankston et al. [4] and Tewarson [5] for lumber, plastics, and liquid fuels, there is no

${ }^{2}$ Nuclear Research Center Negev, Beer-Sheva 84190 , Israel.

Contribution from the National Bureau of Standards, not subject to copyright. 
generally validated correlation allowing one to predict the smoke emission for a large-scale fire based on small-scale results. Bard and Pagni [6] have proposed a correlation in regard to the maximum smoke emission from a flame.

This paper primarily consists of a description of the apparatus developed and results obtained for selected materials for a small-scale apparatus for fire sizes in the $1-10 \mathrm{~kW}$ size range and a large-scale system for fires in the $50-400 \mathrm{~kW}$ size range. The small-scale apparatus has the feature that by increasing the external flux incident on the sample, the specific burning rate of the material can be increased to match the rate obtained in a larger scale fire. A major issue of this study is whether the small and large scale smoke emission properties correlate for the same specific burning rate. The results will also be compared with the prediction of Bard and Pagni [6].

\section{DEFINITION OF SMOKE PROPERTIES}

The most rudimentary smoke quantity is the smoke yield, $\epsilon$, which is defined as the mass of smoke aerosol generated per mass of fuel consumed. This quantity can be determined by a flux method or by a carbon balance method. The flux method simply consists of measuring the smoke collected on a filter, $m_{s}$; the mass loss of the sample, $m_{f}$; and the ratio of the mass flow of air through the exhaust duct to the mass flow through the filter sampler, $\phi$. The smoke yield obtained by the flux method is denoted by $\epsilon_{1}$.

$$
\epsilon_{1}=\left(m_{5} / m_{f}\right) \phi
$$

The carbon balance method involves the determination of $Y_{s}$, the carbon mass in the smoke aerosol, as a fraction of the carbon mass in the total combustion products $\left(\mathrm{CO}_{2}, \mathrm{CO}\right.$, and smoke aerosols). These represent the major carbon containing products of combustion for overventilated combustion. The contribution of unburned gaseous hydrocarbons to the carbon balance was of order 28 or less based on selected tests. By this method, the smoke yield, $\epsilon_{2}$, is obtained as the product of $\mathrm{Y}_{\mathrm{s}}$ and the mass fraction of carbon in the fuel, $F_{c}$.

$\epsilon_{2}=Y_{\mathrm{s}} \mathrm{F}_{\mathrm{c}}$

The carbon balance method has the advantages that it does not require a load cell, and that all the smoke need not be collected in a hood. The one disadvantage is that the mass fraction of carbon in the fuel, $F_{c}$, may vary during the burn, especially in the case of complex fuel mixtures.

In addition to the smoke yield, two specific light extinction areas are measured. The light extinction coefficient $k$ is related to the $1 i g h t$ transmittance, I/I , via Bouguer's law,

$I / I_{0}=e^{-k L}$,

where $\mathrm{L}$ is the path length in meters. The specific extinction area on a fuel-pyrolysates basis, $\sigma_{f}$, is defined by

$\sigma_{f}=\mathrm{k} /\left(\dot{\mathrm{m}}_{\mathrm{f}} / \dot{\mathrm{V}}\right)$,

where $\dot{m}_{f}$ is the fuel mass loss rate and $\nabla$ is the volumetric flow rate of the combustion products through the exhaust duct. As a heuristic example, a value of $1 \mathrm{~m}^{2} / \mathrm{g}$ for $\sigma_{\mathrm{f}}$ means that if the smoke produced by one 
gram of fuel were collected over a $1 \mathrm{~m}^{2}$ area, the light incident on this area would be reduced by a factor e. The quantity $\sigma_{f}$ is 2.3 times larger than the mass optical density introduced by Seader and Einhorn [7], which is based on logarithm to the base 10 , and is identical to modified mass absorbency index used by Tewarson [5].

The specific extinction area on a smoke particulate mass basis, $\sigma_{s}$, is defined by

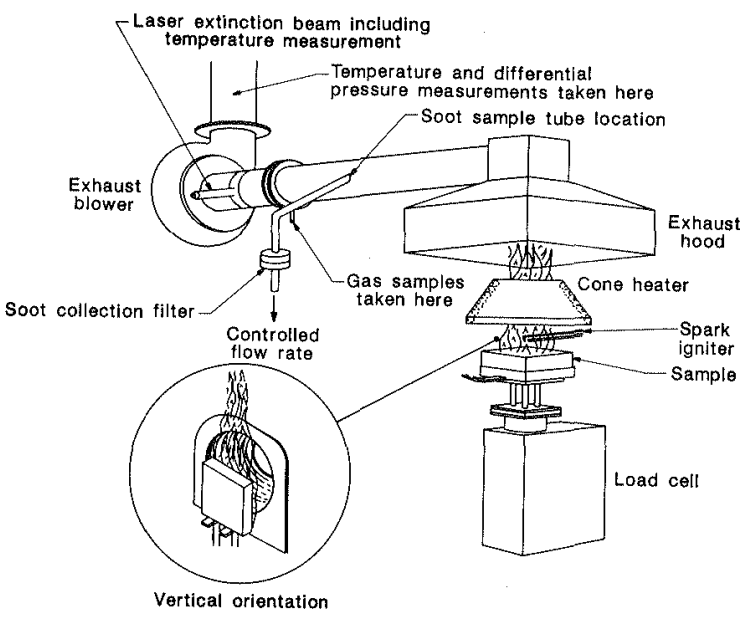

Figure 1. Small scale smoke facility.

$\sigma_{\mathrm{s}}=\mathrm{k} / \mathrm{M}_{\mathrm{s}}$

where $M_{s}$ is the mass concentration of the smoke where the transmittance measurement is being made. The quantity $\sigma_{s}$ is an intrinsic property of the smoke depending on the wavelength of light, the refractive index of the smoke, and on the size and structure of the smoke particulate. The quantities $\sigma_{f}$ and $\sigma_{s}$ are related through the equation

$$
\sigma_{f}=\epsilon \sigma_{\mathrm{s}} \text {. }
$$

\section{EXPERIMENTAL FACILITIES}

\section{Cone Calorimeter}

The Cone Calorimeter was developed by Babrauskas $[8,9]$ to measure the heat release rate and related combustion properties of materials as a function of radiant flux. The conical radiant source (see Fig. I) provides a uniform radiant flux over the $0.01 \mathrm{~m}^{2}$ sample for fluxes up to $100 \mathrm{~kW} / \mathrm{m}^{2}$. After a warmup period for the radiant source to reach steady state, the sample is inserted and ignited via spark. The smoke aerosol and combustion gases rise, pass through the opening in the conical heater (for specimens in the horizontal orientation), go into the exhaust hood through a mixing orifice, and are finally sampled from a horizontal section of pipe, as indicated in figure 1. The fuel burning rate is monitored with a load cell; the heat release rate of the fuel is determined from monitoring the $\mathrm{O}_{2}$ consumption in the exhaust gases [10]. The gases sampled include $\mathrm{CO}, \mathrm{CO}_{2}, \mathrm{O}_{2}, \mathrm{H}_{2} \mathrm{O}$, HCl, and total hydrocarbons.

The smoke particulate is collected on a Pallflex $47 \mathrm{~mm}$ diameter

2 Certain commercial equipment, instruments, and materials are identified in order to adequately specify the experimental procedure. Such identification does not imply recommendation or endorsement by the National Bureau of Standards, nor does it imply that the materials or equipment identified are necessarily the best for the purpose. 
fiber glass filter coated with polytetrafluoroethylene (PTFE). The flow through the filter system is servo-controlled to maintain a fixedfraction mass flow rate relative to the main duct flow rate.

The rapid cooling in the sampling line results in thermophoretic deposition of smoke on the sampling line. An estimate of the smoke deposited in the $6.3 \mathrm{~mm} \mathrm{O.D.} \mathrm{stainless} \mathrm{steel} \mathrm{sampling} \mathrm{line} \mathrm{was} \mathrm{obtained}$ in a series of tests by collecting the smoke on the tube wall after each test by pushing two small pieces of PTFE filter paper through the tube with a PTFE capped plunger. The filter paper and removable PTFE cap were weighed before and after cleaning the tube. The fraction of smoke deposited in the sampling line increased from about $10 \%$ to $25 \%$ as the gas temperature in the exhaust duct was increased from about $175^{\circ} \mathrm{C}$ to $350^{\circ} \mathrm{C}$.

The optical extinction measurement is based on a He-Ne laser, $\lambda=633$ $\mathrm{nm}$, with two silicon photodiodes, one for monitoring the laser intensity and the second to monitor the transmitted intensity. Such a system compensates for the variation in the laser intensity. This compensation is crucial to applying the instrument to weakly smoking fuels because of the small optical path length, about $0.11 \mathrm{~m}$, and the normal drift in the laser output. Other important design features [9] include a rigid mounting isolated from the fan vibrations and the use of purge air to avoid the use of windows.

An estimate of the instrument sensitivity of $\pm 0.03 \mathrm{~m}^{-1}$ was obtained by monitoring the drift in the extinction value over a typical test period of ten minutes for a steady, non-sooting methanol flame. Such a measurement provides a realistic assessment of the effects of fan vibration, tube heating, and turbulent stack flow on the optical alignment. This drift in the extinction coefficient corresponds to only a \pm 0.38 change in the percent transmission over the $0.11 \mathrm{~m}$ path length. This high sensitivity is necessary for monitoring the low smoke output of wood and propane.

\section{Large scale test facility}

This facility accommodates fire sizes up to about $400 \mathrm{~kW}$, which corresponds to about a $0.6 \mathrm{~m}$ heptane pool fire. The fires are situated under a $2.4 \times 2.4 \mathrm{~m}$ collection hood (Fig. 2) with an adjustable exhaust rate up to about $2 \mathrm{~m}^{3} / \mathrm{s}\left(4000 \mathrm{ft}^{3} / \mathrm{min}\right)$. A "tripper" orifice plate with a $0.45 \mathrm{~m}$ diameter is located at the base of the exhaust duct, $0.49 \mathrm{~m}$ diameter, to insure good mixing five duct diameters downstream at thesamplingpoint. Temperature, $\mathrm{CO}_{2}$, and
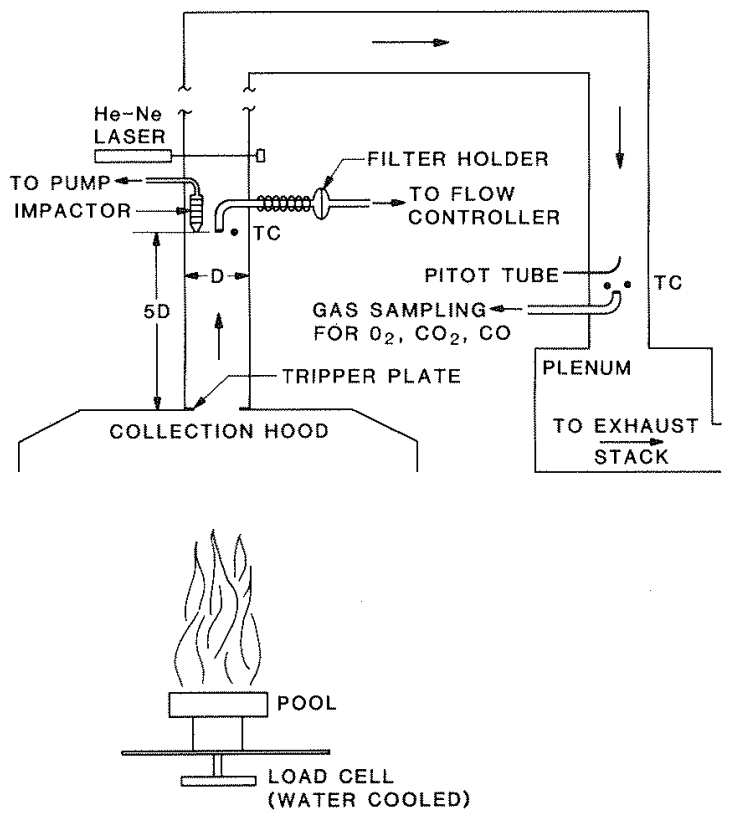

Figure 2. Large scale smoke factity. 
velocity profiles indicate good mixing of $\mathrm{CO}_{2}$, which is taken as a surrogate for the smoke mixing, a slight temperature decrease approaching the duct wall, and a definite asymmetry in the velocity profile perhaps related to the bend in the duct about four diameters downstream of the sampling point.

The mass loss rate of the burning fuel is monitored with a water cooled load cell with a sensitivity of about three grams. The heat release rate is determined from oxygen consumption calorimetry, as is done in the Cone Calorimeter; $\mathrm{CO}$ and $\mathrm{CO}_{2}$ are measured in order to apply the carbon balance method to determine the smoke emission.

The filter collection system allowed for the sequential collection of three filter samples over the course of a test. The transfer line, manifold, and filter holders were all heated to approximately match the stack temperature during the burn. This was done to minimize the evaporation/condensation of the smoke aerosol during transport or on the filter and to minimize the thermophoretic deposition of particles on the walls. The sample flow, about $10 \mathrm{~L} / \mathrm{min}$, and the nozzle inlet, $4.8 \mathrm{~mm}$, were selected to ensure isokinetic sampling. The all-glass construction of the filter collection system allowed ready inspection of deposition and ease in cleaning. The major deposits were found to be at the two bends.

A Gelman Zefluor PTFE filter with a $2 \mu \mathrm{m}$ pore size was used for sample collection. The collection efficiency for this filter is reported to be at least $96 \%$ [11] for particle sizes of $0.035 \mu \mathrm{m}$ and larger. This size range includes essentially all smoke particles. This filter media is not affected by humidity and is the filter of choice for collection temperatures up to $250^{\circ} \mathrm{C}$. Before each experiment, the heated filter system is leak-tested by attaching a dry test meter to the sampling probe.

The extinction measurement is obtained using essentially the same optics and electronics as in the Cone Calorimeter. The only conceptual difference is an $0.48 \mathrm{~m}$ pathlength, compared to a $0.11 \mathrm{~m}$ pathlength in the Cone Calorimeter. A slightly different mechanical mounting arrangement, involving a supporting ring structure, needed to be evolved to properly support the optics over the longer distance. Because of the longer pathlength, however, the sensitivity of the extinction measurement is greater for the large scale apparatus.

\section{RESULTS}

\section{Cone Calorimeter}

The smoke emission was studied for two liquids (heptane and crude oil), and three solids (PMMA, GM38 rigid polyurethane, and wood). The mass fraction of carbon in the fuel, $F_{0}$, for Prudhoe Bay crude oil, rigid polyurethane foam, and sugar pine are $0.86,0.67$, and 0.47 , respectively, based on elemental analysis. The value of $F_{0}$ is needed for obtaining the soot yield based on the carbon balance method.

The results are shown in Table $I$; most entries correspond to an average of more than one test. The PMMA samples were $100 \mathrm{~mm}$ by $100 \mathrm{~mm}$ by 25.4 mm thick, and contained a small amount of carbon black pigment for increased radiant absorption. The mass burning rate of PMMA is approximately tripled by increasing the radiant flux from 25 to 100 $\mathrm{kW} / \mathrm{m}^{2}$; however, in this case both the smoke yield and $\sigma_{f}$ are relatively insensitive to the radiant flux. Eight repeat tests of PMMA in the horizontal configuration resulted in $\epsilon_{1}$ in the range $0.013-0.015$ and $\sigma_{f}$ in the range 0.15 to $0.18 \mathrm{~m}^{2} / \mathrm{g}$ compared to an average value of $0.18 \mathrm{~m}^{2} / \mathrm{g}$ obtained by Tewarson [5] using a tungsten lamp and vacuum phototube 
Table 1. Comparison of Small and Large Scale Smoke Emission Results

\begin{tabular}{|c|c|c|c|c|c|c|c|}
\hline Fuel/Conditions & $\begin{array}{l}\text { Irrad. } \\
\left(\mathrm{kW} / \mathrm{m}^{2}\right)\end{array}$ & $\begin{array}{c}\dot{\mathrm{Q}} \\
(\mathrm{kW})\end{array}$ & $\begin{array}{c}m_{f}^{\prime \prime} \\
\left(g / m^{2}-s\right)\end{array}$ & $\begin{array}{l}\text { Comb. } \\
\text { Eff. }\end{array}$ & $\epsilon_{1}$ & $\left(\mathrm{~m}^{2} / \mathrm{g}\right)$ & $\left(\mathrm{m}^{2} / \mathrm{g}\right)$ \\
\hline \multicolumn{8}{|l|}{ Heptane } \\
\hline \multicolumn{8}{|l|}{ Large Scale } \\
\hline $310 \mathrm{~mm} \mathrm{pool}$ & & 70 & 25 & 0.89 & 0.009 & 0.07 & 7 \\
\hline $500 \mathrm{~mm}$ pool & & 240 & 28 & 0.94 & 0.012 & 0.10 & 8 \\
\hline \multicolumn{8}{|l|}{ Small Scale } \\
\hline \multirow[t]{4}{*}{$85 \mathrm{~mm}$ pool } & 0 & 3 & 10 & 0.99 & 0.010 & 0.06 & 8 \\
\hline & 10 & 7 & 24 & 0.94 & 0.013 & 0.08 & 7 \\
\hline & 20 & 10 & 35 & 0.97 & 0.010 & 0.07 & 8 \\
\hline & 30 & 15 & 58 & 0.98 & 0.006 & 0.05 & 7 \\
\hline \multirow[t]{4}{*}{$60 \mathrm{~mm}$ poo1 } & 0 & 1 & 9 & & 0.015 & 0.15 & 10 \\
\hline & 10 & 3 & 18 & & 0.016 & 0.14 & 9 \\
\hline & 20 & 5 & 38 & & 0.013 & 0.12 & 9 \\
\hline & 30 & 7 & 59 & & 0.013 & 0.12 & 9 \\
\hline \multicolumn{8}{|l|}{ Cruce oil } \\
\hline \multicolumn{8}{|l|}{ Large Scale } \\
\hline $400 \mathrm{~mm}$ pool & & 65 & 14 & $34^{\mathrm{a}}$ & 0.090 & 0.96 & 9.5 \\
\hline $600 \mathrm{~mm}$ pool & & 185 & (18) & & 0.085 & - & 8.7 \\
\hline \multicolumn{8}{|l|}{ Small scale } \\
\hline \multirow[t]{4}{*}{$85 \mathrm{~mm}$ pool } & 0 & 1. & 5 & 41 & 0.098 & 1.06 & 11.7 \\
\hline & 25 & 2 & 11 & 38 & 0.096 & 1.01 & 10.8 \\
\hline & 40 & 4 & 18 & 37 & 0.083 & 1.00 & 12.5 \\
\hline & 50 & 5 & 24 & 36 & 0.084 & 0.98 & 11.7 \\
\hline \multicolumn{8}{|l|}{ Wood } \\
\hline \multirow{2}{*}{\multicolumn{8}{|c|}{$\begin{array}{l}\text { Large Scale } \\
\text { sugar pine }\end{array}$}} \\
\hline & & & & & & & 9 \\
\hline 3 cribs & & 254 & 13 & 0.69 & 0.004 & 0.04 & 9 \\
\hline \multicolumn{8}{|l|}{ Small Scale } \\
\hline \multirow[t]{4}{*}{ Red oak, $100 \mathrm{~mm}$} & 25 & 1 & 9 & 0.55 & 0.002 & 0.02 & 11 \\
\hline & 50 & 1 & 12 & 0.56 & 0.004 & 0.04 & 11 \\
\hline & 75 & 2 & 15 & 0.56 & 0.006 & 0.07 & 13 \\
\hline & 100 & 2 & 19 & 0.60 & 0.011 & 0.09 & 10 \\
\hline \multicolumn{8}{|l|}{$\frac{\text { Polyurethane }}{\text { Large Scale }}$} \\
\hline \multicolumn{8}{|l|}{ Large Scale } \\
\hline 1 crib & & 125 & $12^{b}$ & 0.68 & 0.085 & 0.74 & 9.1 \\
\hline 2 cribs & & 310 & 14 & 0.68 & 0.101 & 0.81 & 8.5 \\
\hline \multicolumn{8}{|l|}{ Sma1l Scale } \\
\hline $100 \mathrm{~mm}$ & 50 & 3 & 5 & 0.85 & 0.080 & 0.89 & 9.4 \\
\hline \multicolumn{8}{|l|}{ PMMA } \\
\hline \multicolumn{8}{|l|}{ Small Scale } \\
\hline \multirow[t]{4}{*}{$100 \mathrm{~mm}$} & 25 & 5 & 16 & 0.96 & 0.015 & 0.16 & 11 \\
\hline & 50 & 7 & 25 & 0.96 & 0.014 & 0.17 & 13 \\
\hline & 75 & 9 & 38 & 0.95 & 0.012 & 0.17 & 11 \\
\hline & 100 & 12 & 47 & 0.96 & 0.016 & 0.16 & 11 \\
\hline The & of & ion & MJ & & & & \\
\hline $\begin{array}{l}\text { The eff } \\
\text { total s }\end{array}$ & tive & f & $t=$ & bust & $\mathrm{s}$ & & the \\
\hline
\end{tabular}


detector. The values of $\epsilon_{1}$ and $\epsilon_{2}$ typically differed by less than $10 \%$. PMMA is seen to be an excellent standard for the smoke measurements because of the constancy of the burning rate and because the smoke emission is high enough for precise measurements both gravimetrically and optically.

For the case of red oak, the smoke measurements are difficult at low fluxes because of low smoke production. Both the smoke yield and the specific extinction area increased by almost a decade with increasing radiant flux. The major peaks in of (Fig. 3) mirror the same peaks seen in the burning rate. The enhanced burning at the later stage results from reduced conductive heat loss when the thermal "wave" propagates through the entire sample. The values of $\epsilon$ and $\sigma_{f}$ for wood burned in a horizontal configuration are approximately twice as large as those burned in a vertical configuration. The values in Table 1 , correspond to an average of horizontal and vertical results.

The mass burning rate of heptane increases more rapidly with increasing radiant flux than for other fuels, because of the higher vapor pressure of heptane. At the highest heat flux, the heat release rate was about $20 \mathrm{~kW}$ for the $85 \mathrm{~mm}$ heptane pool and about $11 \mathrm{~kW}$ for $60 \mathrm{~mm}$ pool. The high exhaust temperature in the extreme case of $20 \mathrm{~kW}$ is thought to be responsible for the decrease in soot emission by almost a factor of two by thermophoretic losses in the tube and/or by enhanced burnout as the flame extends through the mixing orifice. No significant decrease in. smoke emission with increasing flux is observed with the smaller pool. The data collection is terminated before the liquid boils during the later stage of the test. The other 1iquid fuel, Prudhoe Bay crude oil, was floated on water. It was found to emit large amounts of soot, $\epsilon=$ 0.10 , with little dependence on the radiant flux. During the final burning stage, vigorous splattering occurs from the water boiling under the oil.

\section{Large Scale Burns}

The same fuels were burned in the large scale as in the smal1, with the exception that sugar pine was used in place of red oak. Reagent grade nheptane was burned as a $40 \mathrm{~mm}$ layer on water in 0.31 and $0.50 \mathrm{~m}$ diameter pools. A similar configuration was used in burning the Prudhoe Bay crude oil but with slightly larger pools, 0.40

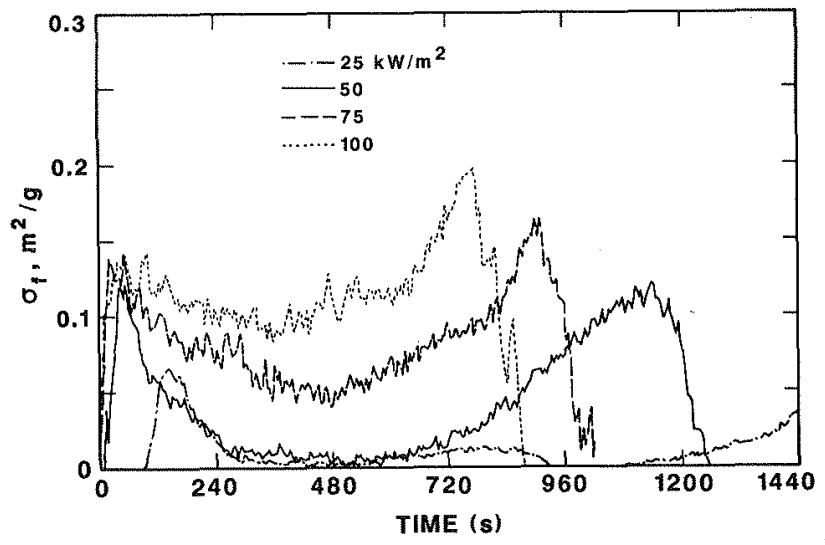
and $0.60 \mathrm{~m}$. The sugar pine and rigid polyurethane were cut into sticks and assembled into layered "crib" structures. The material and crib design is identical to that used by Quintiere and McCaffrey [12] in their study of the burning of wood and plastics in an enclosure. 
The heptane burns provide a good test of the reproducibility of the filter collection measurements, since the burning rate is nearly constant. During the course of a 25 minute experiment, three filter samples were collected for four minutes each. The standard deviations based on two tests and six samples for $\sigma_{f}$ and $\epsilon$ were about $10 \%$ of the mean values and $\epsilon_{1}$ and $\epsilon_{2}$ differ by, at most, 108. The time dependence of $\sigma_{f}$ is

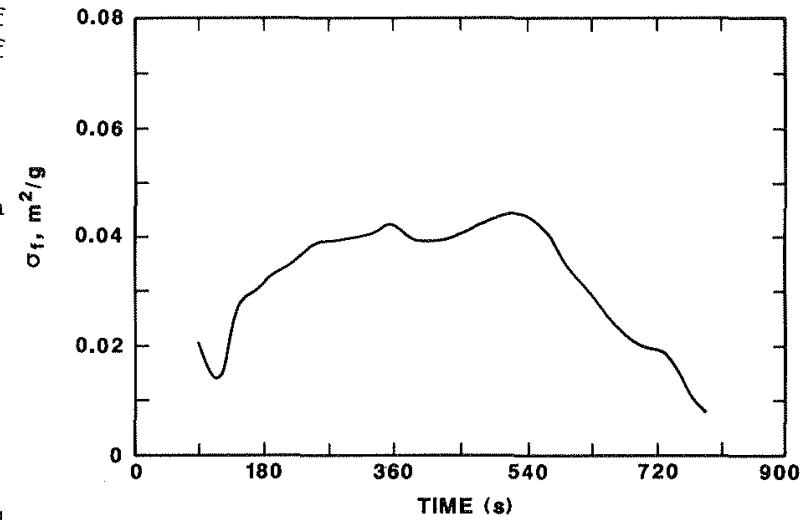
illustrated in Fig. 4

for a burn involving three wood cribs. A second peak is not observed for the burning wood, as was observed with the Cone Calorimeter test; this is because wood sticks in a crib geometry burn from both sides, and there is no heat loss into a support layer.

The large scale results for $\epsilon$ are similar to the Cone Calorimeter results for comparable specific burning rate, $\mathrm{m}_{f}^{\prime \prime}$ (indicated by bold print in Table 1). The mean large scale results and small scale results for the comparable specific burning rate, respectively, are: heptane 0.011 vs 0.013 , Prudhoe Bay crude oil 0.088 vs 0.090 , wood 0.004 vs 0.003 , and rigid polyurethane $0.093 \mathrm{vs} 0.080$. The agreement between large and sma11 scale tests for $\sigma_{f}$ is similar.

one limitation of this method for comparing sma11 and large scale tests is the determination of the mass loss rate per area for complex structures such as cribs. We roughly estimated the effective burning area of the crib to be half of the total surface area of all the individual pieces. The factor of two reduction takes into account the limited burning of undersurfaces, the physical overlap of the individual pieces, and radiation shielding of lower pieces by upper pieces. Also, for wood, we have taken an average of the vertical and horizontal results for the Cone Calorimeter measurements. In addition, the effective burning area decreases 'with time as charring progresses, and this has also been ignored.

The average value of the specific extinction area, $\sigma_{s}$, for each fuel is in the range 8 to $12 \mathrm{~m}^{2} / \mathrm{g}$ for the Cone Calorimeter data, while for the large scale tests the range is less, 8 to $9 \mathrm{~m}^{2} / \mathrm{g}$. The thermophoretic deposition in the Cone Calorimeter sampling probe is possibly responsible for at least part of the larger variability in $\sigma_{\mathrm{s}}$.

\section{DISCUSSION}

Experimental results support a good correlation between small and large scale smoke emission results if the specific mass loss rate of the fuel are the same at the two scales. A demonstration of the general. utility of this approach must await measurements on a wider range of materials, including composites, and a more reliable way of estimating the burning area for complex structures. 
Qualitatively, there are three areas in which large scale fires differ from small fires: burning rate, flame radiation, and fluid flow. Applying an external radiant flux to a small sample enables matching the mass loss rates for small and large scale tests and mimicking, to some extent, the larger fraction of radiant energy in the large fire. It does not reproduce, however, the turbulent mixing of a large scale fire. Data are needed for larger fire scales to determine the significance of the fluid flow in the plume and the radiant feedback in regard to the small scale correlation. This is especially crucial for establishing a data base on mass fires initiated by a nuclear exchange. In the present studies, a slight increase in smoke yield with increasing fire size was observed for the large scale tests for heptane and rigid polyurethane.

Tewarson [13] has proposed that the specific burning rate of a small scale test can be increased to match a large scale burn by increasing the test atmosphere $\mathrm{O}_{2}$ concentration, which raises the flame radiation. For PMMA, which was the one fuel studied both here and by Tewarson, the soot yield obtained for a burning rate of about $25 \mathrm{~g} / \mathrm{s}-\mathrm{m}^{2}$ is 0.016 based on enhanced radiation in this study and 0.012 based on increasing the $\mathrm{O}_{2}$ concentration to a mass fraction of 0.40 in the study by Tewarson. The advantage of changing the burning rate by varying the radiant flux is that the oxygen concentration is kept constant for the small and large scale experiment. It is known that smoke yield is sensitive to the $\mathrm{O}_{2}$ concentration; for example, Tewarson reports [14] more than a doubling in smoke yield for PMMA for a specific mass loss rate of $25 \mathrm{~g} / \mathrm{s}-\mathrm{m}^{2}$ as the $\mathrm{O}_{2}$ concentration is decreased from 0.40 to 0.18 . More data are needed to test the equivalence and utility of the two methods in regard to soot production.

Bankston et al. [4] report a more than two-fold decrease of smoke emission for wood as the radiant flux is increased from $25 \mathrm{~kW} / \mathrm{m}^{2}$ to 50 $\mathrm{k}^{\mathrm{W}} / \mathrm{m}^{2}$, while we observe about a factor of two increase. The difference may result from our collecting smoke only after flaming combustion begins, while in the study by Bankston et al. "pyrolysis smoke" produced before ignition may also have been collected. It is known that the smoke yield from wood during pyrolysis is much greater than during flaming combustion.

Bard and Pagni [6] have proposed a method for estimating the maximum conversion of fuel carbon to soot based on the measurement of the maximum volume fraction of soot in the flame. These estimates are larger than our results based on smoke collected above the flames, since some soot oxidation occurs in the upper portion of the flame. The maximum yields obtained with the Cone Calorimeter are 0.016 for PMMA and 0.013 for wood, compared to Bard and Pagni's prediction of 0.024 for PMMA and about 0.018 for wood.

The values of $\sigma_{\mathrm{s}}$ obtained with the Cone Calorimeter ranged from 8 to $12 \mathrm{~m}^{2} / \mathrm{g}$ and $8-9 \mathrm{~m}^{2} / \mathrm{g}$ for the large scale tests. Seader and Einhorn [7] obtained a mean value of $7.6 \mathrm{~m}^{2} / \mathrm{g}$ based on measurements on several plastics and wood in a chamber using a polychromatic light source. Neuman and Steciak [15] obtained values of $10.3,10.3$, and $10.5 \mathrm{~m}^{2} / \mathrm{g}$ based on flaming combustion of heptane, Douglas fir, and PMMA, respectively. The measurement was performed using an interference filter with peak transmittance essentially matching the HeNe laser wavelength of $633 \mathrm{~nm}$. These results are consistent with the statement that $\sigma_{3}$ for flame-generated smoke is independent of the fuel, though systematic differences among test apparatuses remain to be resolved. Other indications that the nature of the smoke is independent of the source include a similar agglomerate structure for smokes produced in all the large scale tests. Elemental carbon fraction determinations also showed a similar value (75\%, or greater) for all the materials tested [16]. It 
is noteworthy in regard to the potential climatic effects of mass fires initiated by a major nuclear exchange, that these values are significantly larger than the estimate of $5.6 \mathrm{~m}^{2} / \mathrm{g}$ given in the National Academy Report [3].

\section{ACKNOWLEDGEMENTS}

The authors gratefully acknowledge Nelson Bryner and William Twilley for assisting in obtaining and reducing the smoke data. This work was partially funded by The Industry Coalition and by the Defense Nuclear Agency.

\section{REFERENCES}

1. Crutzen, P.J., and Birks, J.W., "The Atmosphere after a Nuclear War: Twilight at Noon," Ambio, 11, pp. 114-125, 1982.

2. Turco, R.P., Ackerman, T.P., Pollack, J.B., and Sagan, C., "Nuclear Winter: Global Consequences of Multiple Nuclear Explosions, "Science, 222, pp. $1283-1292,1983$.

3. Nationa1 Academy of Sciences, "The Effects on the Atmosphere of a Major Nuclear Exchange," National Academy Press, Washington D.C., 1985.

4. Bankston, C.P., Zinn, B.T., Browner, R.F., and Powe11, E.A., "Aspects of the Mechanism of Smoke Generation by Building Materials," Combustion and Flame, 41, pp. 273-292, 1981.

5. Tewarson, A., "Experimental Evaluation of Flammability Parameters of Polymeric Materials," Chapter 3 in Flame Retardant Polymeric

Materials, Vol. 3, M. Lewin, S.M. Atlas, and E.M. Pearce, ed., Plenum Press, N.Y., N.Y., pp. 97-153, 1982.

6. Bard, S., and Pagni, P.J., "Spatial Variation of Soot Volume Fractions in Pool Fire Diffusion Flames," First Symposium (International) on Fire Safety Science, C.E. Grant and P.J. Pagni, ed., pp. 361-369, New York, Hemisphere Pub., 1986.

7. Seader, J.D., and Einhorn, I.N., "Some physical, Chemical, Toxicological, and Physiological Aspects of Fire Smoke," Sixteenth Symposium (Internationa1) on Combustion, The Combustion Institute, Pittsburgh, pp. 1423-1444, 1977.

8. Babrauskas, V., "Development of the Cone Calorimeter - A Bench-Scale Heat Release Apparatus Based on Oxygen Consumption, "NBSIR 82-2611, [U.S.] Nat. Bux, Stand., 1982.

9. Babrauskas, V., Mulholland, G., "Smoke and Soot Data Determinations in the Cone Calorimeter," to appear in proc. of ASTM Symposium on Mathematical Modeling of Fires and Related Fire Test Methods, New Orleans (December 1986).

10. Huggett, C., "Estimation of Rate of Heat Release by Means of Oxygen Consumption Measurements," Fire and Materials, 4, pp. 61-65, 1980.

11.Liu, B.Y.H., Pui, D.Y.H., and Rubow, K.L., "Characterization of Air Sampling Filter Media," Chapter 70 in Aerosols in the Mining and Industrial Work Environment, Vol. 3 Instrumentation, V.A. Marple and B.Y.H. Liu, ed., pp. 989-1038, Ann Arbor Science, Ann Arbor, Mich., 1983.

12. Quintiere, J.Q., and McGaffrey, B.J., "The Burning of Wood and Plastic Cribs in an Enclosure", Vol.1, Nat. Bur. Stand. (U.S.) NBSIR 80-2054, $180 \mathrm{pp}, 1980$.

13.Tewarson, A., Lee, J.L., and Pion, R.F., "The Influence of Oxygen Concentration on Fuel Parameters for Fire Modeling," Eighteenth Symposium (International) on Combustion, The Combustion Institute, Pittsburgh, pp. 563-570, 1981 .

14. Tewarson, A., and Steciak, J., "Fire Ventilation," National Bureau of Standards, Washington, D.C., NBS-GCR-83-423, 22 pp., 1983. 
15. Newman, J.S., and Steciak, J., "Characterization of Particulates from Diffusion Flames," Combustion and Flame, 67, pp. 55-64, 1987.

16.Mulholland, G.W., "Smoke Emission and Properties," paper presented at the Defense Nuclear Agency Global Effects Program Technical Review at Ames Research Center, Moffett Field, Calif., Feb. 25, 1986. 
